\title{
Gamificação de uma sequência didática como estratégia para motivar a atitude potencialmente significativa dos alunos no ensino de óptica geométrica
}

\author{
João Batista da Silva ${ }^{1}$, Gilvandenys Leite Sales ${ }^{1}$, Juscileide Braga de Castro ${ }^{1}$ \\ ${ }^{1}$ Pós-Graduação em Ensino de Ciências e Matemática-Instituto Federal do Ceará (IFCE) \\ Av 13 de Maio, 2081 - 60.040-215 - Fortaleza - CE - Brasil. \\ joaobathista82@hotmail.com, denyssales@gmail.com, \\ juscileide@virtual.ufc.br
}

\begin{abstract}
The purpose of this paper is to investigate the contributions of gamification to motivate meaningful learning in physics classes. For this, a quasi-experimental study was carried out, involving a control group (CG), which had traditional classes, and an experimental group (GE), which had gamified classes with the help of the Moodle Help Class Online environment. The results of the questionnaire showed that the gamification of the didactic sequence motivated the students. The results of the tests showed that the GE obtained normalized gain of learning $(g=0.38)$ superior to the $G C(g=0,11)$. Finally, it is believed that underlying the use of digital technologies in the classroom there must be an adequate and consistent teaching methodology.
\end{abstract}

Resumo. O objetivo deste artigo é investigar as contribuições da gamificação para motivar a aprendizagem significativa nas aulas de Física. Para isso, realizou-se um estudo quase-experimental, envolvendo grupo controle (GC), que teve aulas tradicionais, e grupo experimental (GE), o qual teve aulas gamificada com o auxílio do ambiente Moodle Help Class Online. O resultado do questionário evidenciou que a gamificação da sequência didática motivou os alunos. Os resultados dos testes mostraram que o GE obteve ganho normatizado de aprendizagem $(g=0,38)$ superior ao $G C(g=0,11)$. Por fim, acredita-se que subjacente ao uso de tecnologias digitais em sala de aula deve existir uma metodologia de ensino adequada e consistente.

\section{Introdução}

Grandes são os desafios encontrados no ensino de Física na educação contemporânea: ausência de Tecnologias Digitais de Informação e Comunicação (TDIC) nas aulas, predominância do método de ensino por reprodução/transmissão, ensino centrado no docente ao invés do aluno, aprendizagem mecânica, conteúdos desatualizados, dentre outros. [Moreira 2017]. Este fato aumenta ainda mais a necessidade de aproximar o conteúdo do cotidiano do aluno para que o mesmo possa aprender significativamente [Silva et al. 2015], de maneira que, o ensino de Física possa ser útil para a vida, para a cidadania e para preparar os alunos para lidar com situações e problemas do mundo real.

Segundo Moreira (2012) aprender significativamente é um processo de interação entre conhecimentos prévios do aprendiz e os novos conhecimentos. Nesse processo, os novos conhecimentos adquirem significado para o sujeito e os conhecimentos prévios 
adquirem novos significados ou maior estabilidade cognitiva. Contudo, para que o aluno aprenda os conceitos de óptica de forma significativa, é preciso considerar três elementos constitutivos fundamentais propostos pela Teoria da Aprendizagem Significativa (TAS): a) conhecimentos prévios do aluno; b) material potencialmente significativo; e c) predisposição do aluno para aprender o conteúdo escolar.

Segundo os pressupostos da TAS o conhecimento prévio do aluno é o fator que mais influencia a aprendizagem, todavia ele é uma condição necessária, mas não suficiente, para que a aprendizagem seja significativa [Moreira 2012]. Nesse sentido, é preciso também que o professor faça uso de material potencialmente significativo que apresente significado lógico, coerente, plausível, suscetível de ser logicamente relacionável com qualquer estrutura cognitiva apropriada [Valadares 2011]. Este e os recursos (slides, simuladores computacionais, quizzes, vídeos, aplicativos, jogos, entre outros) devem ser planejados antecipadamente para atingir seus objetivos.

É importante destacar que apesar do empenho das pesquisas em elaborar/promover a utilização de materiais potencialmente significativos no ensino de óptica [Silva et al. 2015; Silva e Sales 2017a], eles também, por si só, não garantem que haja aprendizagem significativa, sendo necessário, portanto, que o próprio aluno tenha uma atitude potencialmente significativa (predisposição em aprender). Segundo Moreira (2012) a predisposição/ motivação é a condição mais difícil de ser satisfeita, o que tem sido, um dos principais desafios para o ensino de Física.

Motivar o aluno para aprender não é uma tarefa trivial, mas complexa, principalmente porque requer conhecimento e aporte teórico adequado. Como consequência dessa complexidade, foi evidenciada uma enorme carência de trabalhos empíricos na literatura que investiguem os efeitos motivacionais proporcionados pela gamificação, dentre eles, o ganho de aprendizagem. Diante dessa carência, o objetivo desse artigo é investigar as contribuições da gamificação para motivar a atitude potencialmente significativa dos alunos no ensino de óptica geométrica.

\section{Gamificação}

O termo "gamificação" foi definido por Deterding et al. (2011) como o uso de elementos de design de game em contextos fora dos games para motivar, aumentar a atividade e reter a atenção do usuário. McGonigal (2011) destacou que quatro elementos são fundamentais em qualquer game: voluntariedade, regras, objetivos e feedbacks.

A voluntariedade implica na aceitação das regras, objetivos e feedbacks. O objetivo é o elemento que direciona o participante de um jogo a se concentrar para atingir o propósito. $\mathrm{O}$ alcance do objetivo é representado pela vitória sobre determinado adversário, ou a conclusão de todos os desafios propostos em um jogo. As regras compõem um conjunto de disposições que limitam as ações dos jogadores e condicionam a realização do jogo, possibilitando que o jogador explore os espaços oferecidos, para desenvolver a criatividade e motivar o pensamento estratégico. A função principal dos feedbacks é informar aos jogadores como está sua relação com os diferentes aspectos que regulam sua interação com a atividade para fomentar motivação.

A estratégia de utilizar elementos de jogos, também tem sido investigada na educação, e em particular no ensino de óptica geométrica, cujo objetivo tem sido 
VII Congresso Brasileiro de Informática na Educação (CBIE 2018)

Anais dos Workshops do VII Congresso Brasileiro de Informática na Educação (WCBIE 2018)

potencializar o processo de aprendizagem. Nesse sentido, Silva e Sales (2017a) destacam que a gamificação consiste na utilização de elementos de design de jogos no ambiente de aprendizagem, não para jogar, mas para motivar, engajar e melhorar o rendimento e desempenho dos alunos. Apesar da gamificação ter se mostrado uma alternativa promissora para promover motivação intrínseca, engajamento e sentimento de realização [Silva e Sales 2017b), um dos desafios na criação de ambientes gamificados é saber como estimular e relacionar efetivamente as duas formas de motivação (extrínseca e intrínseca).

Isto posto, para que o professor possa obter sucesso em suas atividades é interessante que ele conheça pelos menos alguns aspectos teóricos subjacentes à gamificação: a teoria da autodeterminação e a teoria do fluxo. A teoria da autodeterminação (Self-Determination Theory, SDT) se propôs a compreender os componentes das motivações e as três necessidades básicas, inatas, subjacente à motivação intrínseca: autonomia, competência e pertencimento.

A Teoria do Fluxo (Flow) explica quais são os motivos que levam as pessoas a ficarem completamente envolvidas e concentradas em determinadas atividades que não proporcionam nenhum tipo de retorno material ou financeiro. Segundo Csikszentmihalyi (1990) é o equilíbrio entre habilidades e desafios que proporciona a sensação de crescimento, um sentimento de serenidade, sem preocupações pessoais ou com alguma outra coisa ao seu redor, essa é a sensação de estar crescendo além dos limites do ego. Ademais, é na realização de atividades que produzem sensação de prazer, descoberta e crescimento da personalidade ao indivíduo, que está a chave para se alcançar o estado de Fluxo [Csikszentmihalyi 1990].

Conforme descrito nos parágrafos anteriores, percebe-se que não é à toa que a teoria do Fluxo é utilizada nos bons games [Fardo, 2013]. Dessa forma, as implicações dessa teoria para o ensino da Física apontam para uma reflexão didático-pedagógica no que diz respeito a elaborar exercícios e atividades que considerem a importância do conhecimento prévio do aluno. Por fim, Silva e Sales (2017a) enfatizam a necessidade de gamificar o ensino de Física para melhorar a aprendizagem, já que essa disciplina tem sido considerada de difícil compreensão por alunos do Ensino Médio. Isto posto, para sistematizar a utilização de elementos, a presente pesquisa utilizou como estratégia a gamificação de uma sequência didática denominada Unidade de Ensino Potencialmente Significativa (UEPS). A descrição desta sequência e os aspectos metodológicos da pesquisa serão detalhados na próxima seção.

\section{Procedimentos metodológicos}

A abordagem metodológica dessa pesquisa é de natureza quantitativa. Com relação aos procedimentos técnicos, foi realizado um estudo de caso com 49 alunos de duas turmas do $2^{\circ}$ ano do Ensino Médio dos cursos de Técnico Integrado do Instituto Federal de Educação, Ciência e Tecnologia do Ceará (IFCE). A carga horária semanal em ambas as turmas foi de 4 horas. As atividades foram desenvolvidas no decorrer de um semestre, tempo destinado para ensino do conteúdo, conforme as diretrizes da instituição. Como não foi possível utilizar a aleatoriedade na escolha dos sujeitos da pesquisa, foi realizado um delineamento quase-experimental envolvendo grupo controle (GC) com 33 alunos e grupo experimental (GE) com 16 alunos. O GC teve aulas 
VII Congresso Brasileiro de Informática na Educação (CBIE 2018)

Anais dos Workshops do VII Congresso Brasileiro de Informática na Educação (WCBIE 2018)

tradicionais/expositivas ministradas pelo professor $\mathrm{B}$, enquanto o GE teve aulas gamificadas, ministrada pelo professor A.

\section{Gamificação da sequência didática}

A metodologia de ensino foi baseada na sequência didática proposta por Moreira (2011) denominada de Unidade de Ensino Potencialmente Significativa (UEPS), cujo objetivo é facilitar a aprendizagem significativa de tópicos específicos de óptica geométrica. A construção e aplicação desta UEPS foram realizadas conforme os aspectos sequenciais (passos) preconizados por Moreira (2011).

\subsection{Primeiro aspecto sequencial: tópicos específicos e o contrato didático}

Inicialmente apresentou-se aos alunos o plano de ensino da disciplina e os objetivos a serem alcançados, bem como as regras (contrato didático). Explicou-se que o conteúdo seria dividido em fases, cada uma correspondendo a um tópico específico de óptica geométrica. Por conseguinte, foi esclarecido que seriam propostas missões (atividades específicas), individuais e em times, com peso proporcional ao nível de complexidade para sua realização. Por fim, para tornar o plano da disciplina mais claro para os alunos foi utilizada a plataforma Help Class Online, um Ambiente Virtual de Aprendizagem (AVA) customizado a partir da plataforma Moodle.
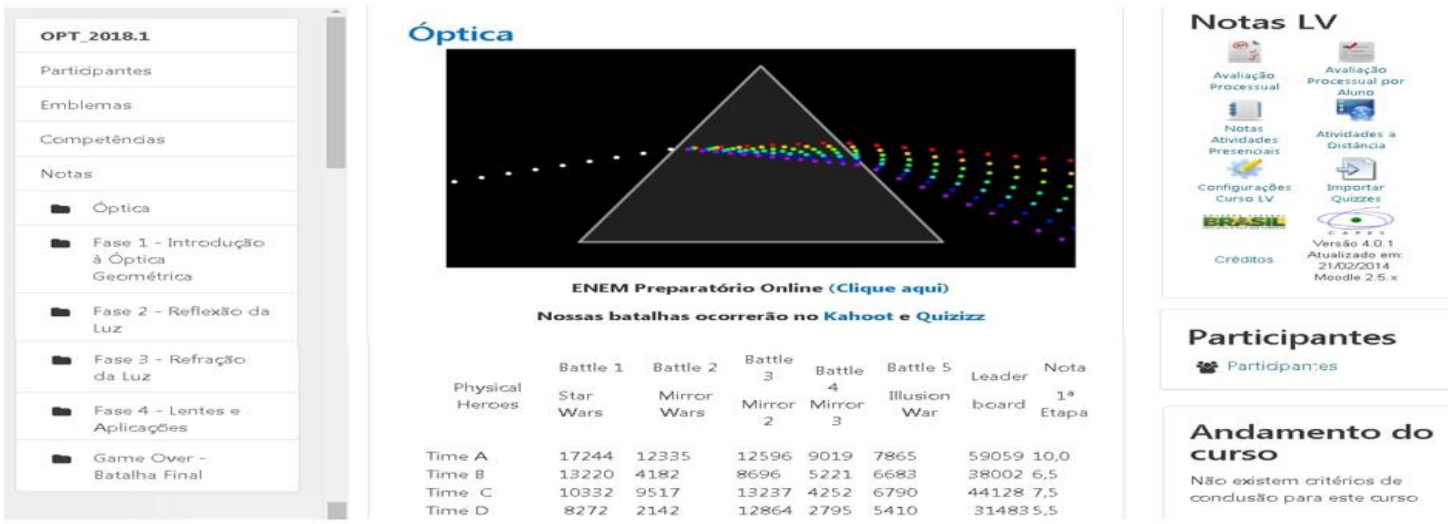

Figura 1 - Design do Help Class Online com o plano da disciplina

O Help Class Online foi utilizado para que o aluno pudesse acompanhar seu desempenho e para auxiliar o professor no gerenciamento da avaliação da aprendizagem, por meio de feedbacks imediatos de suas ações logo após o cumprimento de cada missão específica. A realização desse controle pelo professor, em atividades gamificadas, foi uma das dificuldades apontadas por Domínguez et al. (2013), principalmente no que diz respeito a necessidade de feedbacks imediatos.

\subsection{Segundo aspecto sequencial: implementação da UEPS}

O segundo aspecto sequencial aborda as situações da implementação da UEPS em sala de aula foi dividido em 6 etapas.

Situação inicial: nessa fase foram propostas situações para instigar o aluno a externalizar seus conhecimentos prévios, os quais são relevantes para a aprendizagem significativa dos tópicos de óptica geométrica. Nesse sentido, inicialmente foi realizado um Kahoot sobre fundamentos de óptica geométrica. O Kahoot é considerado uma ferramenta de avaliação gamificada porque ele incorpora alguns elementos de games 
VII Congresso Brasileiro de Informática na Educação (CBIE 2018)

Anais dos Workshops do VII Congresso Brasileiro de Informática na Educação (WCBIE 2018)

como feedback imediato, níveis, pontuação, entre outros [Cavalcante, Sales e Silva 2018].

Situações-problema iniciais: Nessa fase foram propostas situações-problemas, em nível bem introdutório (nível básico), cujo objetivo foi preparar os estudantes para a introdução do conhecimento científico que se pretendia ensinar. Nesse sentido, foi exibido um documentário do Jornal Nacional ${ }^{1}$ sobre problemas gerados com a construção de um prédio de 37 andares em Londres, que acabou "virando" um gigantesco espelho côncavo refletindo a luz do sol e concentrando em um pequeno ponto na calçada, o que, consequentemente, elevou a temperatura local.

O processo de ensino: Nessa fase, foram abordados assuntos mais específicos como reflexão e refração da luz. Como recurso didático foi utilizado o simulador computacional de reflexão e refração da luz ancorado na plataforma PHET $^{2}$. Este recurso foi escolhido por possibilitar, entre outros, a simulação de dois fenômenos acontecendo simultaneamente: reflexão e refração.

Aprofundamento dos conhecimentos em nível de maior complexidade: Nessa fase a missão dada foi que os alunos, em times, calculassem o desvio da luz ao passar pelo prisma óptico. Para isso, eles se reuniram em pequenos grupos para discussão sobre o tema. Ao final, foi solicitado que eles resolvessem um questionário, em nível mais complexo do que os anteriores, integrando os diferentes fenômenos relacionados à luz e a sua propagação.

Avaliação: Ao final de cada tópico foram realizados quizzes (Kahoot e Quizizz), cuja escolha justifica-se por apresentar ranking instantâneo e possibilitar que o aluno crie seu avatar, um personagem que representa o jogador em um mundo virtual [Fardo 2013].

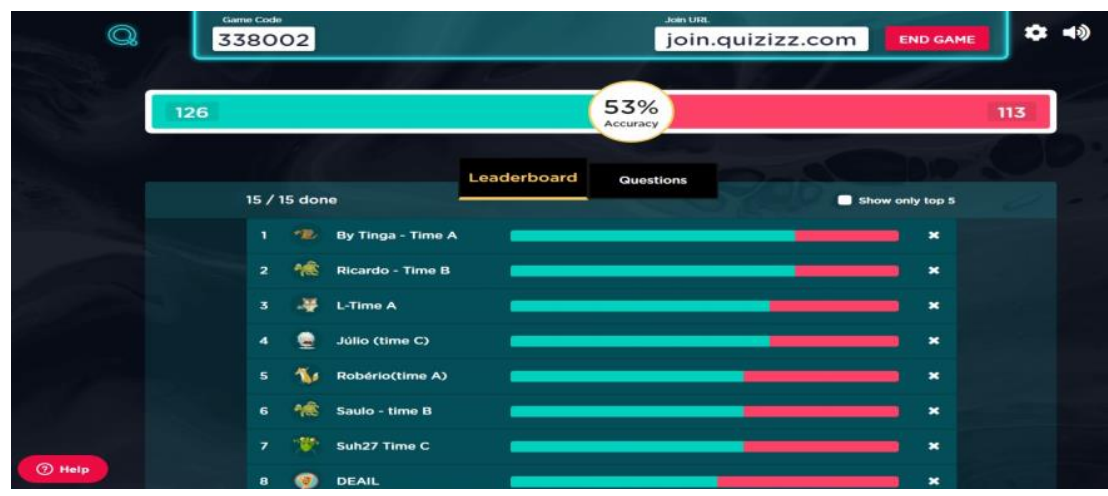

Figura 2 - Resultados parcial em andamento do Quizizz

O avatar é um recurso muito importante na gamificação, principalmente, por evitar que os alunos com baixo desempenho se sintam constrangidos ao ver seu nome no ranking do quizizz, o qual tem a possibilidade de exibe a pontuação instantânea dos alunos.

Encontro final integrador: Nessa fase foi retomado todo o conteúdo ensinado, revisão dos conteúdos de óptica geométrica (reflexão e refração da luz) chamando a atenção para o potencial descritivo e explicativo dos fenômenos, algumas dificuldades

\footnotetext{
${ }^{1}$ Disponível em: Fonte: http://g1.globo.com/jornal-nacional/noticia/2013/09/predio-reflete-luz-do-sol-ejornalista-frita-ovo-na-calcada-em-londres.html

${ }^{2}$ Disponível em: https://phet.colorado.edu/pt_BR/simulation/bending-light
} 
VII Congresso Brasileiro de Informática na Educação (CBIE 2018)

Anais dos Workshops do VII Congresso Brasileiro de Informática na Educação (WCBIE 2018)

inicialmente encontradas na compreensão de conceitos e superação após a aprendizagem da teoria científica.

\section{Apresentação e discussão dos resultados}

A presente seção tem como objetivo apresentar e discutir os resultados obtidos nos testes e no questionário.

\subsection{Resultados e discussão dos testes}

O pré-teste foi aplicado em 15 alunos do GE e 31 alunos do GC, porém apenas 13 alunos do GE e 28 alunos do GC responderam o pós-teste. Dessa forma, decidiu-se utilizar apenas os dados referentes aos alunos que responderam tanto o pré-teste quanto o pós-testes. É importante destacar que o teste (pré e pós) foi o mesmo e que antes da apresentação do conteúdo, os alunos foram informados com antecedência de que seu desempenho nos testes não teria efeito nas notas da disciplina. $O$ teste foi composto por dez questões selecionadas, adaptadas ou elaboradas com base na matriz de competências/habilidades do Exame Nacional do Ensino Médio (ENEM). As respostas foram tabuladas sendo atribuída 1 ponto para a correta e nenhum ponto para a incorreta.

Para a análise estatística, inicialmente, foi realizado o teste de Shapiro-Wilk para verificar se os dados apresentam uma distribuição normal ou não. $\mathrm{O}$ resultado do teste de normalidade do GC $(\mathrm{p}=0,630)$ e do GE $(\mathrm{p}=0,050)$ mostraram indícios de que a amostra não apresentaram uma distribuição normal, o que aponta, portanto, para a utilização de uma estatística não-paramétrica. Deste modo, resolveu-se utilizar o teste $U$ de Mann-Whitney. O teste mostrou que os grupos, na ocasião do pré-teste, não apresentaram diferenças significativas $(\mathrm{U}=148, \mathrm{p}=0,341)$. Com base nestas informações pode-se afirmar que, inicialmente, os grupos eram estatisticamente semelhantes.

\begin{tabular}{ccc}
\hline & Pré-teste & \\
\hline & Grupo Experimental & Grupo Controle \\
\hline Tamanho da amostra (N) & 13 & 28 \\
\hline Soma dos postos (Ri) & 307,0 & 554,0 \\
\hline Mediana & 40,00 & 40,00 \\
U & 148,00 & \\
Z(U) & 0,953 & \\
\hline p-valor (uni-caudal) & 0,170 \\
p-valor (bi-caudal) & 0,341 \\
\hline
\end{tabular}

\begin{tabular}{|ccc}
\hline & Pós-teste & \\
\hline & Grupo Experimental & Grupo Controle \\
\hline Tamanho da amostra (N) & 13 & 28 \\
\hline Soma dos postos (Ri) & 372,0 & 489,0 \\
\hline Mediana & 60,00 & 50,00 \\
$U$ & 83,00 & \\
Z(U) & 2,774 & \\
\hline p-valor (uni-caudal) & 0,003 \\
\hline p-valor (bi-caudal) & 0,005 \\
\hline
\end{tabular}

Tabela 1 - Resultado do teste U de Mann-Whitney para o pré-teste e o pós-teste

Ao final da intervenção foi aplicado o pós-teste em ambas os grupos. O teste $U$ de Mann-Whitney mostrou que após a intervenção os grupos (GC e GE) apresentaram diferenças significativas $(\mathrm{U}=83, \mathrm{p}=0,005)$. Os resultados obtidos apontaram que houve influência significativa da metodologia de ensino gamificada na aprendizagem dos alunos, quando comparada com a metodologia tradicional. Baseado nos pressupostos de Moreira (2011) é possível afirmar que essa diferença significativa evidencia o efeito da a gamificação da UEPS no desempenho do grupo experimental.

Isto posto, resolveu-se mensurar/calcular qual foi o ganho de aprendizagem dos grupos. Para isso, foi realizado um teste de ganho normatizado (Equação 1), modelo proposto por Hake (1998). O cálculo do ganho normatizado é dado pela seguinte equação: 


$$
\mathrm{g}=\frac{\% p o ́ s-\% p r e ́}{100 \%-\% p r e ́}
$$

(Equação 1)

O modelo de Hake (1998) descreve que g é o ganho normatizado, \%pós é a porcentagem de acerto pós-teste aplicado após a implementação da metodologia, \%pré é a porcentagem de acerto do pré-teste aplicado antes da intervenção, e $100 \%$ é a porcentagem máxima de acertos possível de ser alcança. Considerando os critérios de Hake (1998) e Araujo et al. (2017), de que o ganho baixo é apresentado quando com valores de $\mathrm{g}<0,30$, o ganho médio apresenta valores no intervalo $0,30 \leq \mathrm{g}<0,70$ e o ganho é alto quando apresenta valores de $\mathrm{g} \geq 0,70$, o GE obteve ganho médio $(\mathrm{g}=0,38)$.

\begin{tabular}{|c|c|c|c|c|c|}
\hline \multirow[b]{2}{*}{ Grupos } & \multirow[b]{2}{*}{$N$} & Pré-teste & Pós-teste & \multirow{2}{*}{$\begin{array}{c}\text { Ganho absoluto } \\
\text { (Pós-Pré) }\end{array}$} & \multirow{2}{*}{ Ganho normatizado } \\
\hline & & $\%$ de acertos & $\%$ de acertos & & \\
\hline Experimental & 13 & $47,27 \%$ & $67,27 \%$ & $20,00 \%$ & 0,38 \\
\hline Controle & 28 & $38,21 \%$ & $45,00 \%$ & $6,79 \%$ & 0,11 \\
\hline
\end{tabular}

Tabela 2 - Resumo dos resultados do desempenho dos grupos

O ganho do GE é compatível com os resultados obtidos com a aplicação de metodologias de aprendizagem ativa [Araujo et al. 2017] e está acima dos ganhos de ( $\mathrm{g}$ $=0,36)$ encontrado por Laubersheimer, Ryan e Champaign (2017) e de $(\mathrm{g}=0,27)$ alcançado por Tolentino e Roleda (2017), ambos valores encontrados na literatura internacional. É importante destacar que até o presente momento não foram encontrados estudos na literatura nacional que apresentasse valores de ganhos normatizados em atividades gamificadas.

\subsection{Resultados e discussão dos questionários}

Para avaliar a motivação do aluno, foi aplicado o modelo de questionário baseado no modelo ARCS (Attention, Relevance, Confidence and Satisfaction), desenvolvido por John Keller. Analogamente à pesquisa de Poffo (2016), optou-se por utilizar apenas 16 das 36 assertivas do modelo original do ARCS, as quais, por necessidade, foram adaptadas para que pudessem atingir o objetivo desta pesquisa, que é verificar a motivação proporcionada pela gamificação. Um passo muito importante tomado durante a implementação aplicação do questionário ARCS foram o esclarecimento sobre o anonimato do respondente e a sensibilização dos alunos para a importância da avaliação da metodologia.

O ARCS já foi avaliado por testes psicométricos, todavia, como foram utilizados apenas 16 itens do modelo original, se fez necessário verificar a confiabilidade dos itens selecionados por meio do coeficiente $\alpha$ de Cronbach, por ser considerado um dos indicadores mais importantes da qualidade de uma escala de medida. Os resultados apresentaram valores $\alpha=0,795$, o que significa que o questionário possui alta confiabilidade e se mostrou válido para investigar o nível de motivação [Poffo 2016]. Sendo assim, a análise do questionário será baseada na proposta de Poffo (2016) de que, quanto maior for a porcentagem de respostas 4 (Concordo parcialmente) e 5 (Concordo totalmente) melhor avaliada será o nível de motivação proporcionada pela metodologia.

O questionário utilizou uma escala Likert de cinco pontos (discordo totalmente, discordo parcialmente, indiferente, concordo parcialmente, concordo totalmente) em cada assertiva, as quais foram classificadas em quatro categorias sobre a qualidade da motivação. As categorias do ARCS buscam explicar as relações entre a expectativa 
VII Congresso Brasileiro de Informática na Educação (CBIE 2018)

Anais dos Workshops do VII Congresso Brasileiro de Informática na Educação (WCBIE 2018)

subjetiva do aluno obter sucesso e sua satisfação pessoal, o que são essenciais para o emprego de esforço em uma determinada atividade.

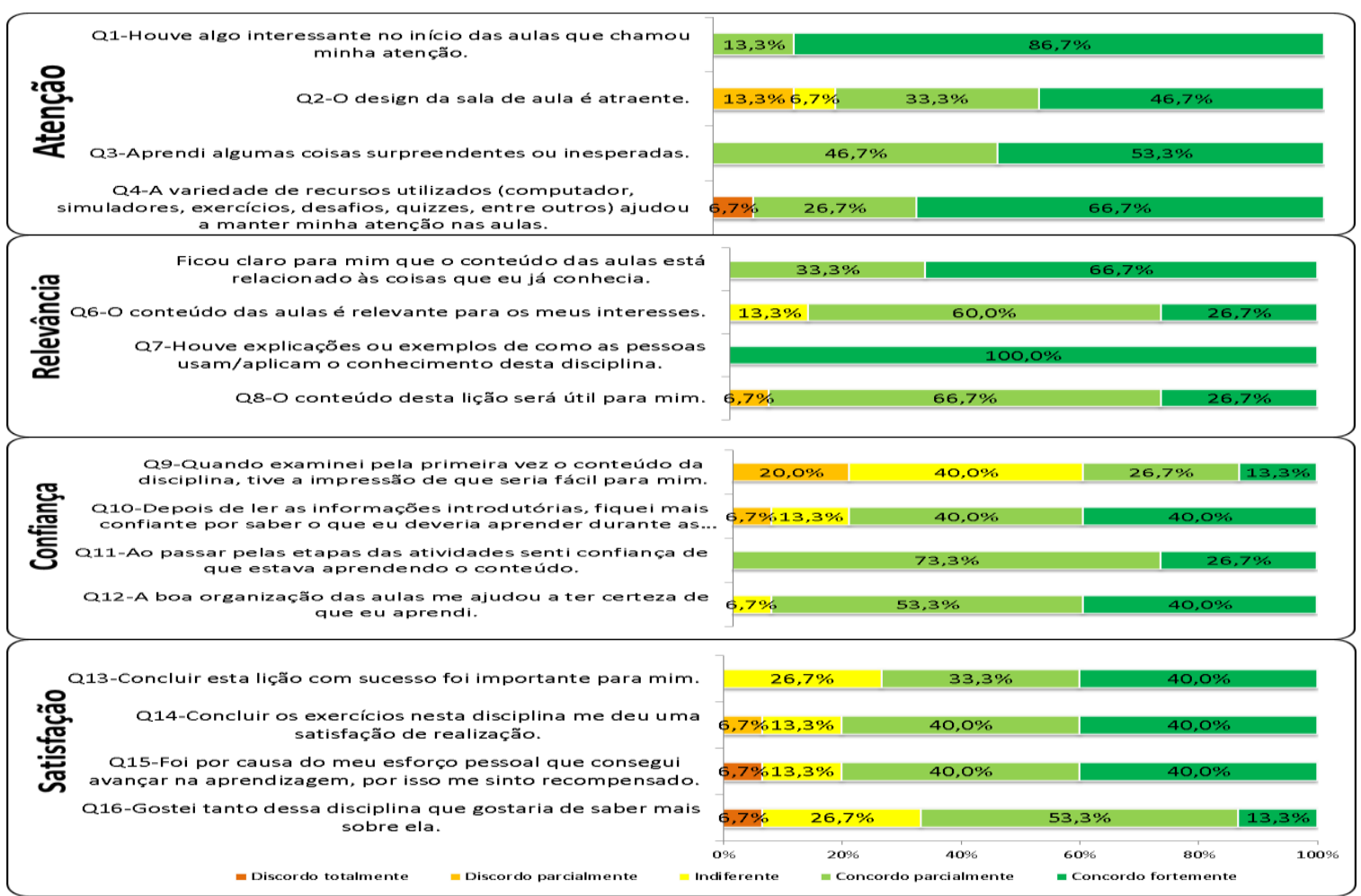

Figura 3- Instrumento de avaliação da qualidade da motivação baseado no modelo ARCS

A categoria Atenção teve como objetivo verificar se a metodologia aplicada proporcionou um nível satisfatório de atenção dos alunos durante o período de aprendizagem. Os resultados mostraram que $100 \%$ da turma concordou que no início das aulas foi realizado alguma atividade que chamasse/despertasse a atenção do aluno, $80 \%$ concordou que o design da sala era atraente para proporcionar aprendizagem, $100 \%$ do grupo concordou aprendeu coisas surpreendentes ou inesperadas, e 93,4\% concordou que a variedade de recursos utilizados ajudou a manter a atenção do aluno nas aulas. Os resultados dessa categoria foram bastante positivos e evidenciaram que as atividades, conteúdos e recursos utilizados ajudaram a manter a atenção do aluno, que é uma condição inicial motivar a aprendizagem. Nesse sentido, um aluno destacou que "a metodologia em si, com o uso da tecnologia faz com que os alunos despertem o interesse de forma ampla, tal coisa está associada à juventude, além de que os quizzes estimulam o raciocínio lógico" (Aluno 12).

A categoria Relevância teve como objetivo investigar se o conteúdo ensinado está intimamente ligado às necessidades ou interesses pessoais dos alunos para produzir uma atitude positiva durante o processo de aprendizagem. Os resultados mostraram que para $100 \%$ da turma ficou claro que o conteúdo das aulas está relacionado às coisas que ele já conhecia, acredita-se que este resultado tenha sido influenciado pelo fato de que nesta pesquisa foram considerados os pressupostos da TAS, os quais consideram a importância dos conhecimentos prévios para o processo de aprendizagem. Além disso, $86,7 \%$ concordou que o conteúdo foi relevante para seus interesses pessoais, $100 \%$ da turma concordou totalmente durante as aulas houve explicações ou exemplos de como as pessoas usam/aplicam o conhecimento desta disciplina, sendo esta a assertiva mais 
VII Congresso Brasileiro de Informática na Educação (CBIE 2018)

Anais dos Workshops do VII Congresso Brasileiro de Informática na Educação (WCBIE 2018)

bem avaliada do questionário, e 93,4\% concordaram que o conteúdo ministrado na lição seria útil para a sua vida pessoal.

A categoria Confiança teve como objetivo investigar houve expectativas positivas nos alunos em relação ao sucesso na aprendizagem, de maneira que ele mesmo possa perceber que está progredindo pelo seu próprio esforço. Apenas $40 \%$ da turma concordou que examinaram pela primeira vez o conteúdo da disciplina, tiveram a impressão de que o conteúdo seria fácil, este foi o item de todo o questionário com menor aceitação, e maior indiferença (40\%). Este resultado vai de encontro ao que afirmou Aguiar (2009) de que apesar da óptica geométrica ser um campo com importantes aplicações práticas que deveriam facilitar a aprendizagem, a concepção inicial do grupo em relação ao material foi bem diferente. Ademais, $80 \%$ concordou que ao ler as informações introdutórias da lição ficaram mais confiantes por saberem sobre o que deveriam aprender durante as aulas, $100 \%$ concordou que ao passarem pelas etapas das atividades eles sentiram confiança de que estavam aprendendo o conteúdo, e 93,3\% concordaram que a boa a organização das aulas ajudou a na aprendizagem.

A categoria Satisfação teve como objetivo investigar se houve sentimento de realização sobre as experiências de aprendizagem. 73,3\% concordou que concluir a lição com sucesso foi importante para o aluno, $80 \%$ concordou que ao concluírem os exercícios da disciplina, tiveram uma satisfação de realização, $80 \%$ acreditam que foi por causa de seu esforço pessoal que eles conseguiram avançar na aprendizagem e por isso se sentiram recompensados, e apenas $66,6 \%$ dos informantes afirmaram que tinham gostado da disciplina e gostaria de saber mais sobre ela. Verificou-se que nessa categoria o nível de satisfação foi moderado. Sabe-se que são muitas as variáveis que influenciam no aspecto motivacional do aluno, dentre elas: a personalidade do aluno, sexo, idade, ambiente, necessidades de realizações pessoais, dentre outras. Dessa forma, o aprendizado de Física, especificamente o de óptica geométrica, depende fortemente da motivação, do envolvimento e da satisfação do aluno para proporcionar desenvolvimento/aperfeiçoamento de habilidade/competências necessários na contemporaneidade.

\section{Considerações finais}

O objetivo dessa pesquisa foi investigar as contribuições da gamificação para motivar a atitude potencialmente significativa dos alunos no ensino de óptica geométrica. Baseado no resultado do questionário é possível concluir que a estratégia de gamificar uma sequência didática motivou os alunos. Os resultados dos testes que indicaram que o GE obteve ganho normatizado médio $(\mathrm{g}=0,38)$ superior ao $\mathrm{GC}$, o qual utilizou aulas tradicionais é possível concluir que a gamificação e aplicação da UEPS além de motivar os alunos forneceu evidências de aprendizagem significativa. Diante da carência de evidências empíricas na literatura sobre o ganho de aprendizagem proporcionados pela gamificação, acredita-se que esta pesquisa possa contribuir para a área de gamificação aplicada ao ensino de Física. Além disso, acredita-se que subjacente à utilização eficaz das TDIC em sala de aula deve existir metodologias de ensino que sejam adequadas e consistentes. Como trabalhos futuros sugere-se que pesquisas semelhantes investiguem os efeitos dessa estratégia em outras áreas do conhecimento como: Matemática, Química, Biologia, entre outras. 
VII Congresso Brasileiro de Informática na Educação (CBIE 2018)

Anais dos Workshops do VII Congresso Brasileiro de Informática na Educação (WCBIE 2018)

\section{Referências}

Araujo, A. V. R. et al. (2017) "Uma associação do método Peer Instruction com circuitos elétricos em contextos de aprendizagem ativa". Revista Brasileira de Ensino de Física, v. 39, n. 2, e2401, 2017.

Cavalcante, A. A.; Sales, G. L. Silva, J. B. (2018) "Digital technologies in Physics education: an experience report using the Kahoot as a tool of evaluation". Research, Society and Development, v.7, n. 11, p. 01-17.

Csikszentmihalyi,M.(1990)Flow:The Psychology of Optimal Experience.HarperCollins.

Deterding, S. et al.(2011) "From game design elements to gamefulness: defining gamification". In Proceedings of the International Academic Mindtrek Conference Envisioning Future Media Environments.

Domínguez, A. et al. (2013) "Gamifying learning experiences: practical implications and outcomes". Computers and Education, v. 63, p. 380-392, 2013.

Fardo, M. L. (2013) "A gamificação como estratégia pedagógica: estudo de elementos dos games aplicados em processos de ensino e aprendizagem". Dissertação (Mestrado) - Universidade de Caxias do Sul.

Hake, R. R. (1998) "Interactive- engagement vs. traditional methods: A six thousand student survey of mechanics test data for introductory physics courses". American Journal of Physics, AAPT, v. 66, n. 1, p. 64-7.

Keller, J. M. (2009) Motivational Design for Learning and Performance:The ARCS Model Approach. Springer.

Laubersheimer, J.; Ryan, D.;Champaign, J. (2016) "InfoSkills2Go: Using Badges and Gamification to Teach Information Literacy Skills and Concepts to College-Bound High School Students", Journal of Library Administration, v. 56, n.8, p. 924-938.

Mcgonigal, J. (2011) Reality is broken: why games make us better and how they can change the world. Nova Iorque: The Penguin Press.

Moreira, M. A.(2017) "Grandes desafios para o ensino da física na educação contemporânea”. Revista do Professor de Física, v. 1, n. 1, p. 1-13.

Moreira, M. A.(2012)“i Al afinal, qué es aprendizaje siginificativo?”.Qurriculum, n.25, p.29-56.

Moreira, M. A. (2011)“Unidades de Enseñanza Potencialmente Significativas". Aprendizagem Significativa em Revista, 1(2): 43-63.

Poffo, Marcio. (2016) "Utilização da gamificação para motivar a aprendizagem: um estudo de caso em engenharia de software". Dissertação (Mestrado) - Univali.

Silva, J. B. et al. (2015) "Mudança conceitual em óptica geométrica facilitada pelo uso de TDIC". In workshop de informática na escola. Maceió.

Silva, J. B., et al. (2018) "Tecnologias digitais e metodologias ativas na escola: o contributo do Kahoot para gamificar a sala de aula". Revista Thema, v. 15, n. 2.

Silva, J. B.; Sales, G. L.(2017a) "Gamificação aplicada no ensino de Física: um estudo de caso no ensino de óptica geométrica". Acta Scientiae, v.19, n. 5.

Silva, J. B.; Sales, G. L. (2017b) "Um panorama da pesquisa nacional sobre gamificação no ensino de Física". Tecnia, v. 2, n. 1, p. 105-121.

Tolentino, A. N.; Roleda, L. S. (2017) "Learning Physics the Gamified Way". In Proceedings of the DLSU Research Congress. Manila. Philippines.

Valadares, J. (2011) "A teoria da aprendizagem significativa como teoria construtivista". Aprendizagem Significativa em Revista, v. 1, n. 1, p. 36-57. 